\title{
A novel model predictive-fuzzy logic hybrid controller design for D-STATCOM in wind energy distribution systems
}

\author{
Yanmaz K..$^{1,}$, Altas I.H. ${ }^{2}$ and Mengi O.O. ${ }^{3}$ \\ Department of Electronics and Automation, Giresun University, Giresun, Turkey \\ Department of Electrical and Electronics Engineering, Karadeniz Technical University, Trabzon, Turkey \\ Department of Energy Systems Engineering, Giresun University, Giresun, Turkey \\ Received: 31/05/2017, Accepted: 15/06/2017, Available online: 30/01/2018 \\ *to whom all correspondence should be addressed: e-mail: kenan.yanmaz@giresun.edu.tr
}

\begin{abstract}
Wind energy is a resource that does not require any fuel or feedstock to be treated, refined or transported. It does not produce air pollution and hazardous waste. Because of these, wind energy, one of the major renewable energy sources, has been widely used in recent years. In this work, a three-phase distribution static synchronous compensator (D-STATCOM) is demonstrated for power quality enhancement in wind energy distribution systems. A fivelevel cascaded inverter is used to implement the DSTATCOM. D-STATCOM is controlled to compensate the reactive power, balances the load and eliminate harmonics. A novel control algorithm is based on the indirect current control system with synchronous reference frame theory for generating the gating pulses of Voltage Source Inverter (VSI). This proposed control system has one model predictive controller and two modified fuzzy logic controllers. The performance of the three-phase DSTATCOM is validated for power quality enhancement with different loads through software implementation using Matlab/Simulink environment. The effectiveness of the proposed approach is verified through simulation studies.
\end{abstract}

Keywords: wind turbine, D-STATCOM, fuzzy logic controller, indirect current control, multilevel cascaded inverter.

\section{Introduction}

In parallel to the rapid growth of industrialization all over the world, energy demand has been increasing exponentially. The rapid increase in the world population also increases the need for energy per capita. Therefore, the need for new energy sources has arisen. Numerous governments and companies have been allocating resources about in creating of new energy sources. Many scientists are also making an effort to develop environmentally friendly new sources.

The production of energy from conventional energy resources is quite harmful to the environment although it is cheap. These harmful effects are air pollution, water pollution and solid waste and soil pollution. Especially, the harmful gases emitted from funnels of thermal power plants to the environment causes serious damages such as lung cancer. The thermal power plants disturb the existing temperature balance when they discharge water they use after installation. This imbalance can cause lethal effects on aquatic organisms. The fume components emitted from funnels of the thermal power plants leak into the soil over time and thus, soil pollution occurs. Nuclear power plants also have similar effects. They cause serious environmental effects in case of an accident. They harbor hazardous effects that affect both human health and wildlife, and future generations. Especially, radioactive leakage problems continue their adverse effects over the years. Furthermore, they cause climate changes. Besides these, the environment is damaged in all the stages of extraction, transfer and consumption of the resources.

All of the harmful effects lead to the searching of resources that can be an alternative to fossil fuels. Concurrently, fossil fuel reserves have been rapidly depleting. Therefore, scientists have focused on new alternative energy sources. The most important renewable energy sources are solar, wind and hydrogen energies. These sources also play an important role in reducing greenhouse gas emissions. They are much more environmentally friendly than the conventional energy sources. Especially wind energy among these sources attracts more attention due to its lower cost per unit and ability to generate energy in almost all conditions. For this reason, the use of wind energy has been increasing rapidly.

Wind turbines convert mechanical energy obtained from the wind into the electrical energy (Kim and Lu, 2010). The wind turbines do not emit hazardous gases into the environment during the stage of power generation (Mirmousavi, 2015). They do not include hazardous wastes and do not have the effects that can change the ambient temperature. Besides, their adverse effects on natural life are very rare. Unlike other sources, they do not become a threat to human health.

For efficient use of energy from wind and protection of environment, it is necessary to improve the efficiency of the use of energy resource and the use of energy (Butkus et al., 2012). Wind turbines running independently from 
the network are not affected from its adverse effects. However, reactive powers they need are required to be produced. Furthermore, they need special solutions to eliminate harmonics and voltage fluctuations arisen from loads. To solve these problems, Flexible AC Transmission Systems (FACTS) are used (Abdelsalam and Sharaf, 2012). One of the FACTS devices is Static Synchronous Compensator (STATCOM). STATCOM has been used increasingly instead of conventional devices such as switched capacitor groups and Static Var Compensator (SVC) to improve the power quality. FACTS devices such as STATCOM are also used in power distribution systems and called Distribution STATCOM (D-STATCOM). D-STATCOM, with advanced power electronics, is adapted to distribution systems (Sun et al., 2004). D-STATCOM is used to improve the power quality in distribution systems as an inverterbased device. The D-STATCOM device removes the reactive power and voltage fluctuations generated by loads. Electrical machines cause inductive effects because of their windings and these effects are resolved through the capacitors. Capacitors which is owned by D-STATCOM structure, do this task by using or removing from the circuit when it is necessary (Rao et al., 2000).

In the literature, many wind turbine emulators are used. This system is created by an electrical machine shaft that models' propeller connecting to another electrical machine. Generator as squirrel cage induction machines, synchronous machines, permanent magnet direct current machine is widely used (Whaley-Ertasgin et al., 2006; Kojabadi et al., 2004).

Many methods are used to control D-STATCOM. Structure actually contains one voltage-controlled inverter (Rao et al., 2000). But this inverter can be made with a multi-level, also can be made in different types with different power electronics connection shapes (Peng, 2001). Indirect current control method based on synchronous reference frame theory has been used here for the D-STATCOM control (Escobar et al., 2004; Norouzi and Sharaf, 2003). Within this structure, $\mathrm{PI}$ and fuzzy logic-based PI controllers are used (Altas et al., 2009).

The choice of modulation technique is also important in DSTATCOM control system. In the literature, different Pulse Width Modulation techniques such as Carrier-based Pulse Width Modulation (Naderi and Rahmati, 2008), multi-level space vector modulation (Narayanan and Ranganathan, 2002) and selected harmonic elimination pulse width modulation (Dahidah and Agelidis, 2008) are used.

In this study; reactive power compensation is made by examining structure of the D-STATCOM in the networkindependent island-type wind turbine system. D-STATCOM contains 5-level VSI. A novel control algorithm is based on the indirect current control system with synchronous reference frame theory for generating the gating pulses of VSI. This proposed control system has one Model Predictive controller (MPC) and two Modified Fuzzy Logic Controllers (MFLC). Differences from D-STATCOM structure is activated or not has been demonstrated. System simulation is made up in MATLAB/Simulink environment.

\section{Materials and Methods}

Wind energy system with D-STATCOM is shown in Figure 1. D-STATCOM structure consists of VSI, DC-link capacitors, control circuit, and coupling inductor. VSI has five-level cascaded $\mathrm{H}$-bridge structure. DC-link capacitors meet the $\mathrm{dc}$ voltage that is required for the inverter circuit. Control circuit is used to control power to the load from the wind turbine. Coupling inductor is used to connection to the common connection point.

5 level cascaded H-bridge based VSI is used here. More precise control is possible with the increase of level of the inverter. However, it is becoming more difficult to control accordingly due to increased number of switching elements. This delicate structure in the system is formed by using the 24 IGBT. Increasing the number of elements in the upper levels increases system cost and that doesn't have a particularly positive effect in the system. Limited impact doesn't compensate for the cost.

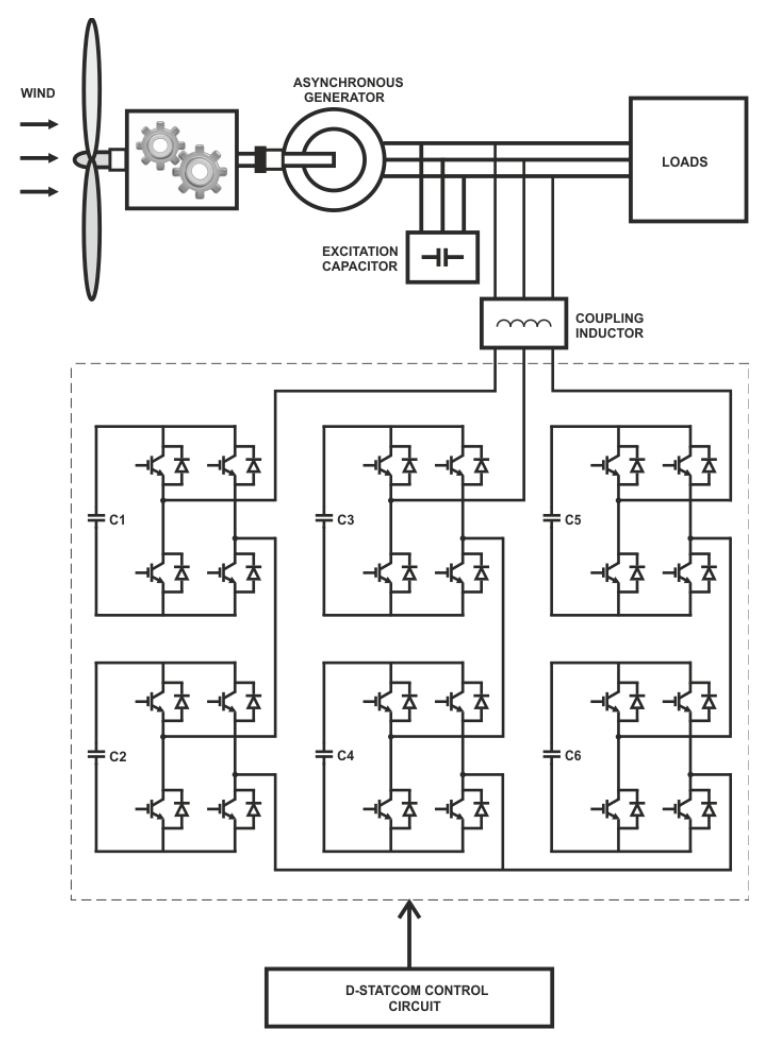

Figure 1. Overview of the complete system diagram

As shown in Figure 1, VSI of D-STATCOM has five level cascaded $\mathrm{H}$-bridge structure. There are a total of $6 \mathrm{H}$-bridge including 2 in each phase. Inverter output voltage for one phase is the sum of the output voltage in the respective phase of each $\mathrm{H}$-bridge. Each arm of the $\mathrm{H}$-bridge consists of two series-connected switching elements. These switches are switched in opposite ways to protect shortcircuit the DC-link capacitors. Dead time delay circuit is used to prevent switching elements from being transmitted at the same time. H-briidge connected DC-link capacitors meet DC voltage that is required for VSI.

VSI is connected in parallel to the power system via coupling inductor. The common serial port connection 
inductance $\left(Z_{\text {st }}\right)$ is used to ensure this connection in the common port. The size of the reactive current flowing toward the connection inductance $\left(i_{s t}\right)$ is proportional to the difference of D-STATCOM AC output voltage $\left(v_{s t}\right)$ with supply voltage at a common connection point $\left(v_{p c c}\right)$. This is achieved by controlling the amplitude of the voltage of the DC link capacitors $\left(v_{D C}\right)$.

The equation in $A B C$ coordinate axis control system is a difficult equation in terms of design because variables on the $A C$ side of the mathematical model are timedependent. Therefore it is converted to two-phase coordinate axis with the coordinate axes ABC PARK transformation. $A B C$ coordinate axis matrix is transformed with the help of the Equation (1), PARK transformation matrix to two phases simultaneously rotating the coordinate axes.

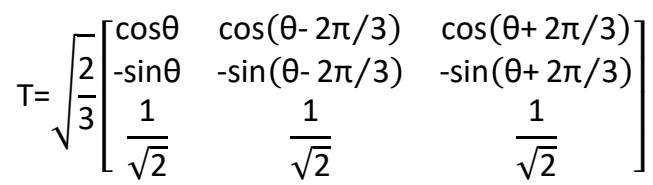

With this transformation $\mathrm{i}_{\text {stdq }}=\mathrm{T}^{*} \mathrm{i}_{\mathrm{abc}}$ is obtained.

The Equation (2) can be written after D-STATCOM current $\left(i_{\text {st }}\right)$ related conversion:

$$
\mathrm{i}_{\mathrm{st}}= \pm \mathrm{i}_{\text {std }} \pm \mathrm{ji} \mathrm{i}_{\text {stq }}
$$

Here $\mathrm{i}_{\text {std }}$; active current used for charging / discharging status and $\mathrm{i}_{\text {stq }}$; link inductance and reactive current flowing to $Z_{\text {st }}$

PLL calculates the phase angle of the supply voltage required for the load current $i_{l q}$, D-STATCOM output voltage and current to be converted to dq axes transformation with the park transformation. Then the controller generates switching signals to drive the switching elements of the inverter. Sinusoidal PWM (SPWM) technique was used to produce this switching signals (Naderi and Rahmati, 2008).

Transfer function of D-STATCOM in dq axis is as in Equation (3).

$$
\left[\begin{array}{l}
v_{s t d} \\
v_{s t q}
\end{array}\right]=\left[\begin{array}{l}
v_{p c c d} \\
v_{p c c q}
\end{array}\right]-L_{s t} \frac{d}{d t}\left[\begin{array}{l}
i_{s t d} \\
i_{s t q}
\end{array}\right]-\omega L_{s t}\left[\begin{array}{c}
i_{s t q} \\
-i_{s t d}
\end{array}\right]
$$

Block diagram of a synchronous reference frame theory indirect current control system for D-STATCOM obtained from (3) is shown in Figure 2. This dc voltage is kept constant in the control system and reference voltage needed to be produced by the inverter are obtained based on reference active and reactive power.

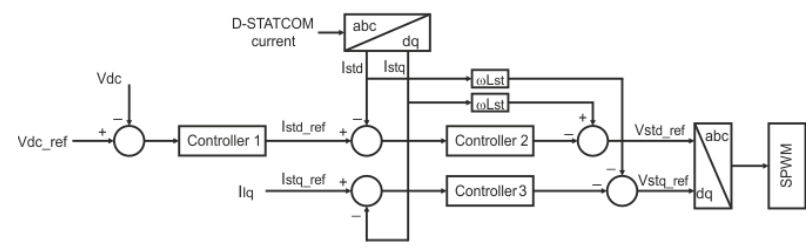

Figure 2. Basic model of D-STATCOM controller

\subsection{Modified Fuzzy Logic Controller}

Modified fuzzy logic controller (MFLC) scheme is shown in Fig. 3 where it consists of the fuzzifier, rule base-fuzzy inference and defuzzifier (Altas and Sharaf, 2007). Fuzzifier, the first subsystem of the MFLC, converts the exact inputs to fuzzy values. These fuzzy values are sent to rule base unit and processed with fuzzy rules in fuzzy inference (Altas and Mengi, 2013).

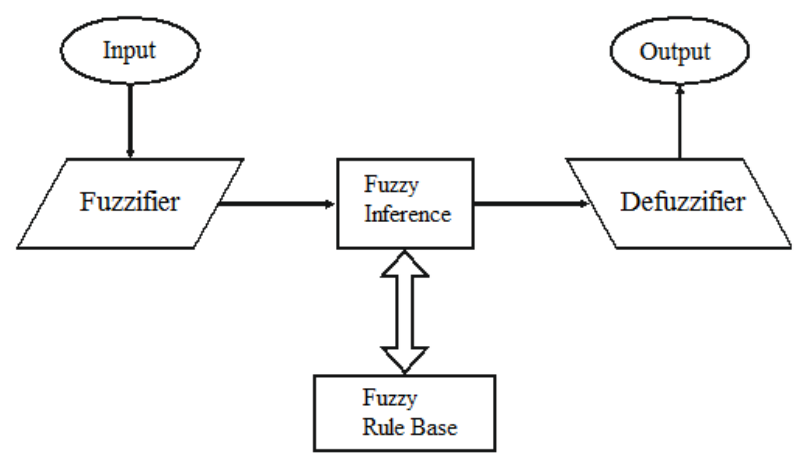

Figure 3. Modified fuzzy logic controller scheme

These derived fuzzy values are sent to defuzzifier unit. In this subsystem, the fuzzy results are converted to exact output values.

The models of all MFLC's units are developed in Matlab/Simulink environment. MFLC used in this system has 5 rules. The operation with 3 rules and 7 rules are also tested. However, MFLC with 3 rules could not satisfy the desired system performance while MFLC with 7 rules give the same performance as 5 rules. Detailed information is given in the article name (Altas and Sharaf, 2007).

\subsection{Model Predictive Controller}

In addition to the conventional PID control technique, which is frequently used in industrial applications, Model Predictive Controllers (MPCs), one of the advanced control techniques, are also used. The beginning of the first application of the MPC in the field of power electronics began in the 1980s. The first applications in power electronics are high power systems with low switching frequency. With the development of fast and powerful microprocessors, applications of MÖD in the field of power electronics have increased considerably. From time to time horizon, common elements of such controllers use the system model to predict future behavior of variables and select the best working condition by minimizing the cost function. Figure 4 shows the basic structure of the MPC (Danayiyen et al., 2017).

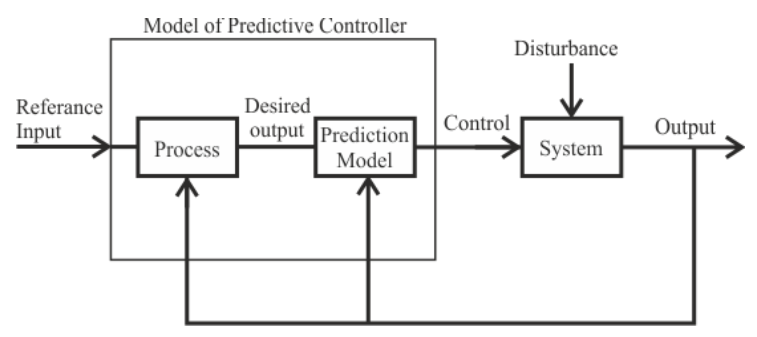

Figure 4. Basic model of MPC controller 
Equations (4) and (5) show the state space model equations of the MPC.

$$
\begin{aligned}
& x(k+1)=A x(k)+B u(k) \\
& y(k)=C x(k)+D u(k)
\end{aligned}
$$

The equation of the cost function is shown Equation (6)

$$
J=f(x(k), u(k), \ldots, u(k+N))
$$

\section{Results and discussion}

D-STATCOM simulation were conducted with different sample experiments. Matlab/Simulink software package is used to accomplish this. Wind turbine is used to main source in this simulation study. The sampling frequency for the control system has been chosen as $10 \mathrm{kHz} .1 \mathrm{kHz}$ frequency is selected for switching elements within the $D$ STATCOM. Figure 5 shows the proposed predictive-fuzzy hybrid control diagram for D-STATCOM.

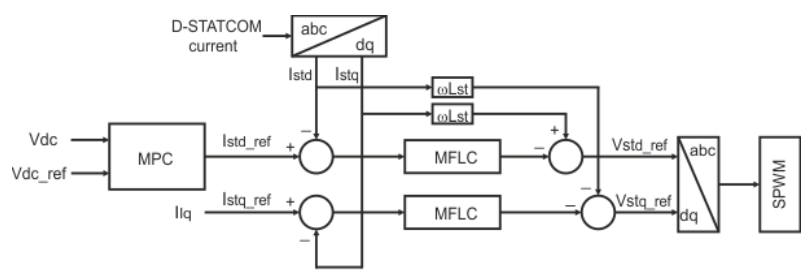

Figure 5. Proposed control diagram of D-STATCOM

The system parameters listed in Table 1 are used for

\begin{tabular}{|c|c|}
\hline \multicolumn{2}{|c|}{ System Parameters } \\
\hline System voltage (V) & Three phase $380 \mathrm{~V} 50 \mathrm{~Hz}$ \\
\hline DC-link voltage (Vdc) & $200 \mathrm{~V}$ \\
\hline DC-link capacitance (Cdc) & $4700 \mu \mathrm{F}$ \\
\hline Sampling frequency (f) & $10 \mathrm{kHz}$ \\
\hline Switching frequency (fsw) & $1 \mathrm{~Hz}$ \\
\hline Coupling resistance (Rf) & $56 \mathrm{~m} \Omega$ \\
\hline Coupling inductance (Lf) & $6 \mathrm{mH}$ \\
\hline Load 1 & 1kW Resistive \\
\hline Load 2 & $4 \mathrm{~kW}$ induction motor \\
\hline Load 3 & 3kW Resistive (0.3-1s) \\
\hline Load 4 & $1 \mathrm{~kW}+2 \mathrm{k} \operatorname{Var}(0.4-1 \mathrm{~s})$ \\
\hline Load 5 & $1 \mathrm{~kW}+2 \mathrm{kVar}(0.6-1 \mathrm{~s})$ \\
\hline
\end{tabular}
simulation study.

Table 1. The system parameters used in simulation

Figure 6 shows the change in reactive components of load and D-STATCOM currents under different load conditions. Figure 6 (a) shows the result of simulation study with MFLC$\mathrm{PI}$ controller. Figure 6 (b) shows the result of simulation study with MPC-MFLC controller. When these two graphs are compared, it seen that the fluctuation in the DSTATCOM current are less and the reference load current is observed more successfully as a result of the simulation study with MPC-MFLC controller.
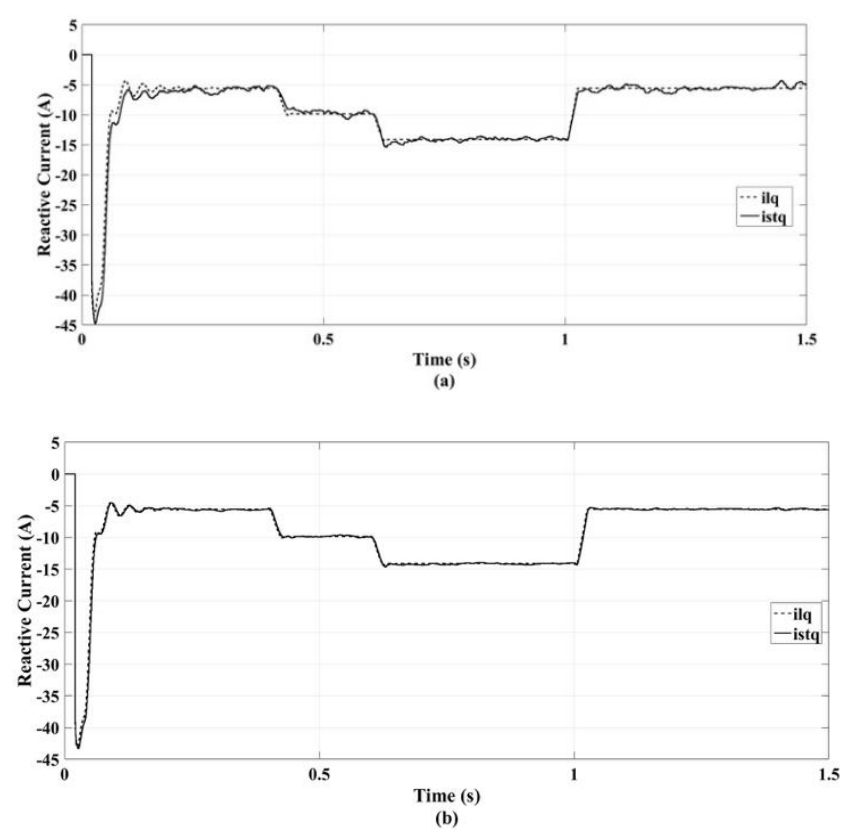

Figure 6. Reactive component of load and D-STATCOM currents (a) MFLC-PI, (b) MPC-MFLC

Figure 26 shows the $d$ and q components of the source current. As seen in this figure, reactive power is at $0 \mathrm{~V}$ level as expected for both simulation study.
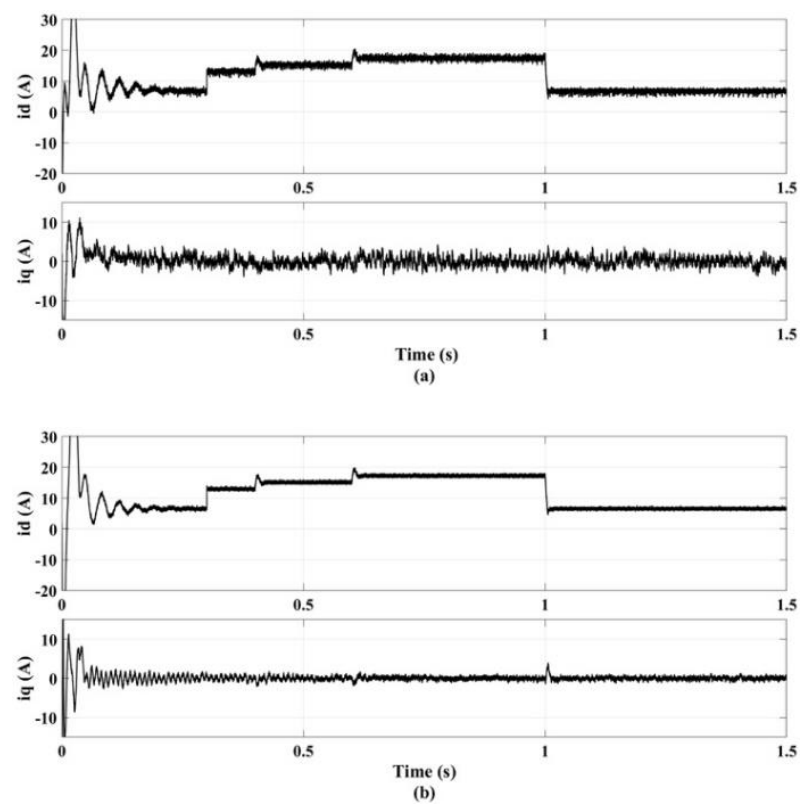

Figure 7. $d$ and q components of the source current (a) MFLC-PI, (b) MPC-MFLC

The changes in source voltage and current are shown in Figure 8. When analyzed in terms of power factor, it is clearly seen that there is no phase difference between source voltage and current. 

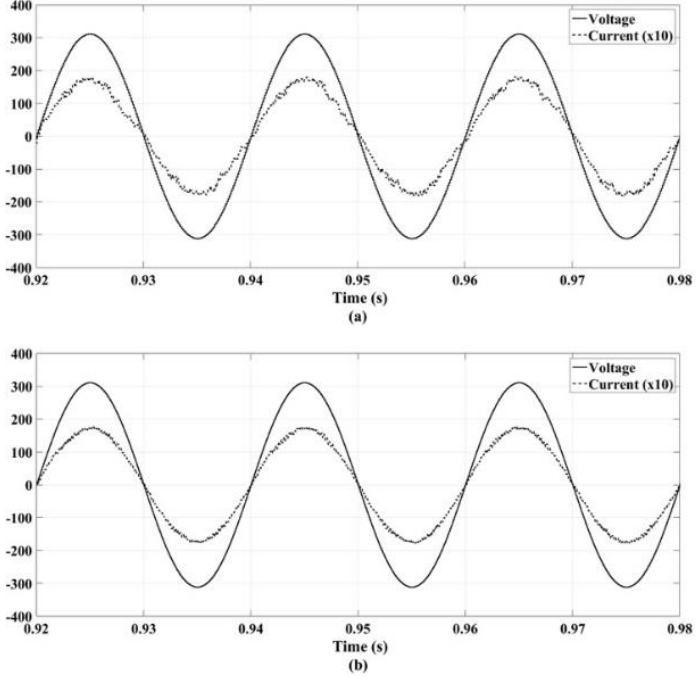

Figure 8. Waveform of source voltage and current (a) MFLC-PI, (b) MPC-MFLC

The waveforms of D-STATCOM output current and voltage are shown in Figure 9.
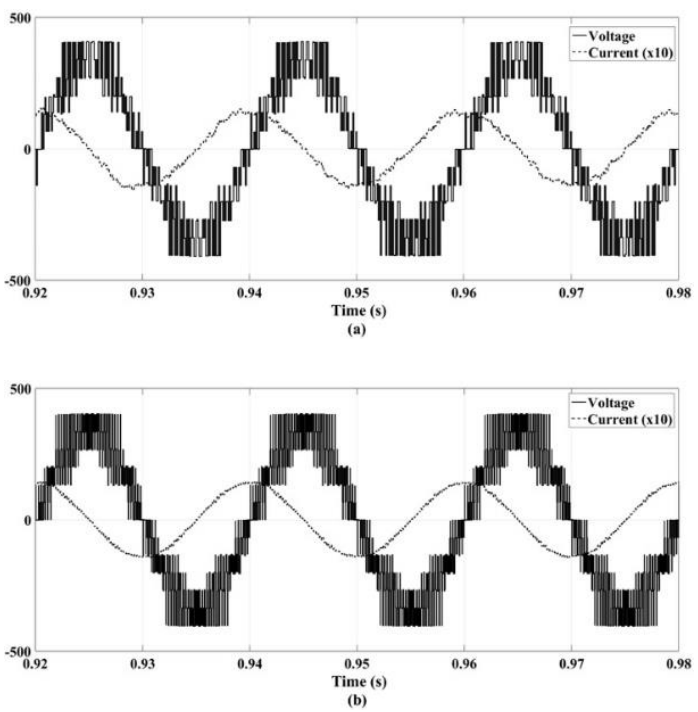

Figure 9. Waveforms of D-STATCOM output current and voltage (a) MFLC-PI, (b) MPC-MFLC

D-STATCOM's total DC-link voltage waveform is shown in Figure 10. The simulation result using the MPC-MFLC control method give better results both at maximum overshoot time and settling time.

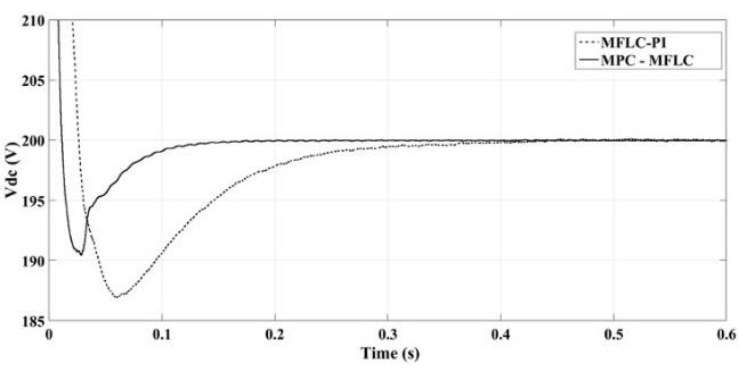

Figure 10. DC-link voltage waveform of D-STATCOM
The $\mathrm{H}$-bridge voltage waveforms for a phase of the fivelevel cascaded $\mathrm{H}$-bridge inverter-based D-STATCOM are shown in Figure11. Vah1 and Vah2 voltages represent two $\mathrm{H}$-bridge voltages in phase A of the VSI of D-STATCOM. Va is the sum of two $\mathrm{H}$-bridge voltages in one phase of DSTATCOM.

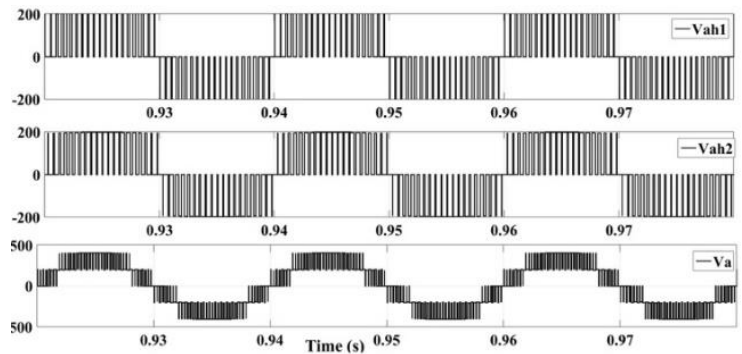

Figure 11. Voltage waveforms in a phase of D-STATCOM

\section{Conclusions}

This study has been studied based on the cascaded $\mathrm{H}$ bridge five level inverter-based D-STATCOM structure for wind energy systems. For efficient use of energy from wind and protection of environment, a new control circuit for controlling D-STATCOM device has been proposed. Mixed control techniques are used in proposed control scheme. MPC controller is used to control the DC side of DSTATCOM and the MFLC controllers for controlling the $d$ and q components of output current of D-STATCOM are used.

The results of MPC-MFLC controller and MFLC-PI controller are compared. The system using the MPC-MFLC controller is seen to be successful when examined in terms of power factor, voltage regulation and reactive compensation.

\section{Acknowledgements}

This work is supported by Turkey Scientific and Technological Research Council of Turkey (TUBITAK) with 114E474 numbered project, titled "Design and Implementation of a Smart STATCOM in Small Scale Wind Turbines".

\section{References}

Abdelsalam A.A. and Sharaf A.M. (2012), A novel FACTS compensation scheme for power quality improvement in wind smart grid, 25th IEEE Canadian Conference on Electrical and Computer Engineering, 1-4.

Altas I.H. and Mengi O.O. (2013), A fuzzy logic voltage controller for off-grid wind turbine supercapacitor renewable energy source, International Conference on Electrical and Electronics Engineering, 62-66.

Altas I.H. and Sharaf A.M. (2007), A generalized direct approach for designing fuzzy logic controllers in matlab/simulink gui environment, International Journal of Information Technology and Intelligent Computing, 4(1).

Altas I.H., Ozkop E. and Sharaf A.M. (2009), A novel active filter strategy for power mitigation and quality enhancements in a stand-alone WECS, International Conference on Electrical and Electronics Engineering, I-88-I-91.

Dahidah M.S.A. and Agelidis V.G. (2008), Selective harmonic elimination PWM control for cascaded multilevel voltage 
source converters: A generalized formula, IEEE Trans. Power Electron., 23(4), 1620-1630.

Danayiyen Y., Altas I.H. and Sahin E. (2017), Model Predictive Control of a DC-DC Buck Converter, Sigma Journal of Engineering and Natural Sciences, 8(2), 91-97.

Donatas B., Raimondas G. and Jurgis M. (2012), Research of Equivalent and Maximum Value of Noise Generated by Wind Power Plants, Journal of Environmental Engineering and Landscape Management, 20(1), 27-34.

Escobar G., Stankovic A.M. and Mattavelli P. (2004), An adaptive controller in stationary reference frame for D-statcom in unbalanced operation, IEEE Trans. Ind. Electron., 51(2), 401-409.

Kim H.S., Lu D.D.-C. (2010), Wind energy conversion system from electrical perspective -A survey, Smart Grid and Renewable Energy, 1, 119-131.

Kojabadi H.M., Chang L. and Boutot T. (2004), Development of a novel wind turbine simulator for wind energy conversion systems using an inverter-controlled induction motor, IEEE Transaction on Energy Conversation, 19(3), 547-552.

Mirmousavi S.H. (2015), Assessment of wind energy potential in East Azarbaijan province of Iran (case study: Sahand Station), Global NEST Journal, 17(2), 418-425.

Naderi R. and Rahmati A. (2008), Phase-shifted carrier PWM technique for general cascaded inverters, IEEE Trans. Power Electron., 23(3), 1257-1269.

Narayanan G. and Ranganathan V.T. (2002), Extension of operation of space vector PWM strategies with low switching frequencies using different overmodulation algorithms, IEEE Trans. Power Electron., 17(5), 788-798.

Norouzi A.H. and Sharaf A.M. (2003), A novel control scheme for the STATCOM stability enhancement, in Proc. IEEE Trans. Transmiss. Distrib. Conf. Expo., 24-29.

Peng F.Z. (2001), A generalized multilevel inverter topology with self-voltage balancing, IEEE Transactions on Industry Applications, 37(2), 611-618.

Rao P., Crow M.L. and Yang Z. (2000), STATCOM control for power system voltage control applications, IEEE Transaction on Power Delivery, 15(4), 1311-1317.

Sun J., Czarkowski D. and Zabar, Z. (2004), Voltage flicker mitigation using PWM-based distribution STATCOM, Proceedings of the IEEE Power Engineering Society Summer Meeting, 1, 616-621.

Whaley D.M., Ertasgin G., Soong W.L., Ertugrul N., Darbyshire J., Dehboeni H. and Nayar C.V. (2006), Investigation of a low-cost grid-connected inverter for small-scale wind turbines based on a constant-current source PM generator, 32nd Annual Conference on IEEE Industrial Electronics, 4297-4302. 